\title{
Empowering professionals to lead Haemophilia care
}

Sandra Dodgson, Jenny Bryan, Simon Fletcher, Cathy Harrison, Clare Ibbs, April Jones, Paul McLaughlin, Gráinne O’Brien, Sharon Varney, Anne Wareing, Pamela Wick

Abstract: Members of the multi-disciplinary team involved in delivering haemophilia care face a range of significant clinical and service leadership challenges. These include the developing treatment landscape,

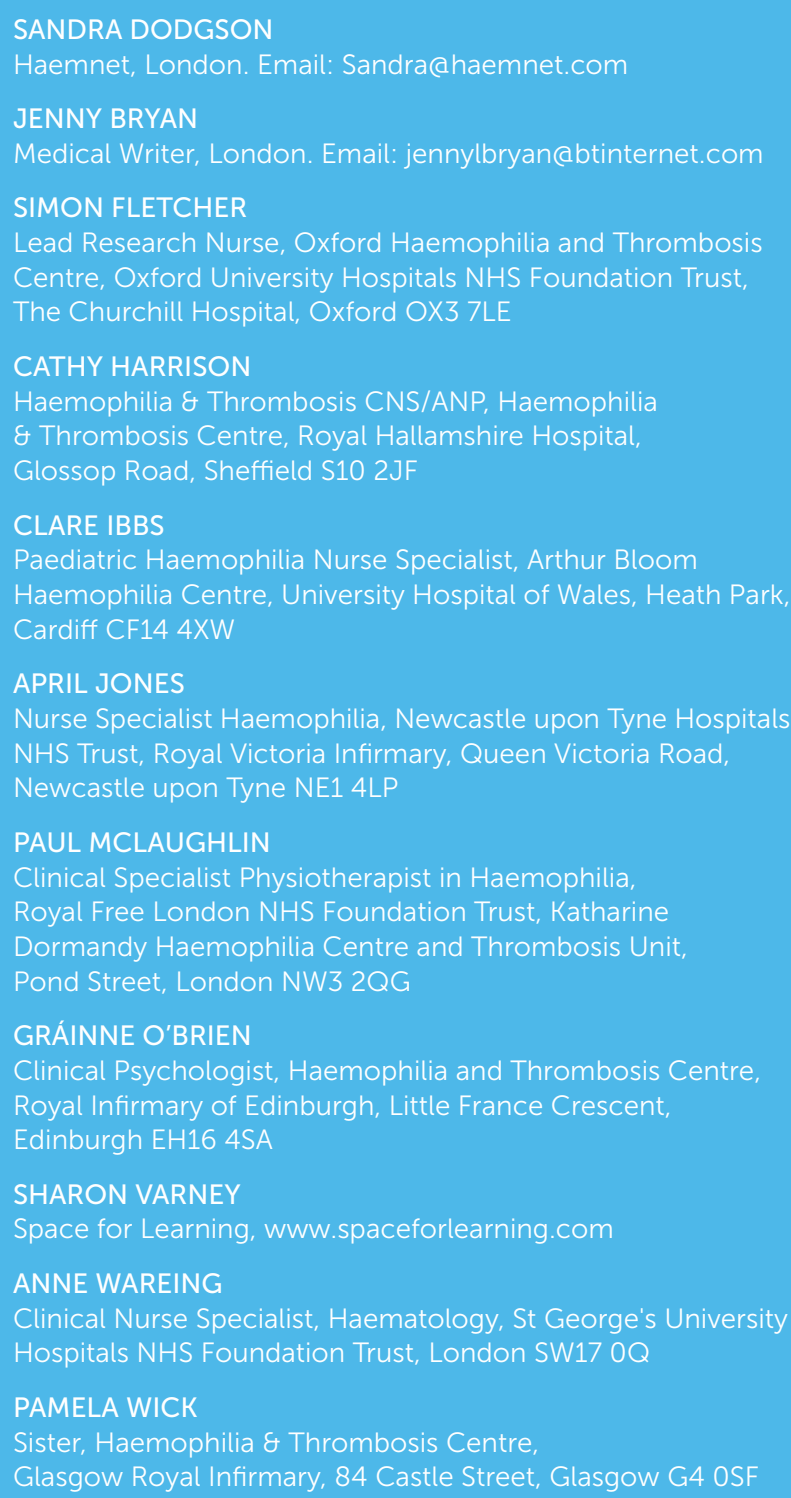

the drive towards individualised care, an uneven age structure among haemophilia nurses and constrained budgets. Faced with such challenges, the ASPIRE programme has been established to encourage and support a new generation of haemophilia leaders who are committed to improving haemophilia care across the UK, and beyond. The programme is open to healthcare professional from multiple disciplines, and is designed to support the development of a leadership community comprising members of the haemophilia care team in a way that contrasts with hierarchical leadership and management courses more typically found in the NHS.

Keywords: Leadership, Multidisciplinary team, Communities, Leadership communities

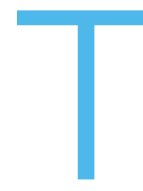

he evolving treatment landscape, the drive towards individualised care for people with haemophilia, and constrained budgets bring significant opportunities and challenges for members of the multidisciplinary team (MDT) in leading clinical services. Alongside this, surveys conducted by the UK's Haemophilia Nurses Association (HNA) show an uneven age structure among haemophilia nurses, with likely retirement of many senior haemophilia nurses in the UK over the next 3-5 years, raising concerns about future clinical and service leadership.

If we are to make the most of these opportunities, there is a need to encourage and support potential leaders within haemophilia care teams who can engage colleagues and initiate and progress service development across all roles, in order to improve haemophilia care across the UK. To address these challenges, the ASPIRE programme has been established to encourage and support a new 


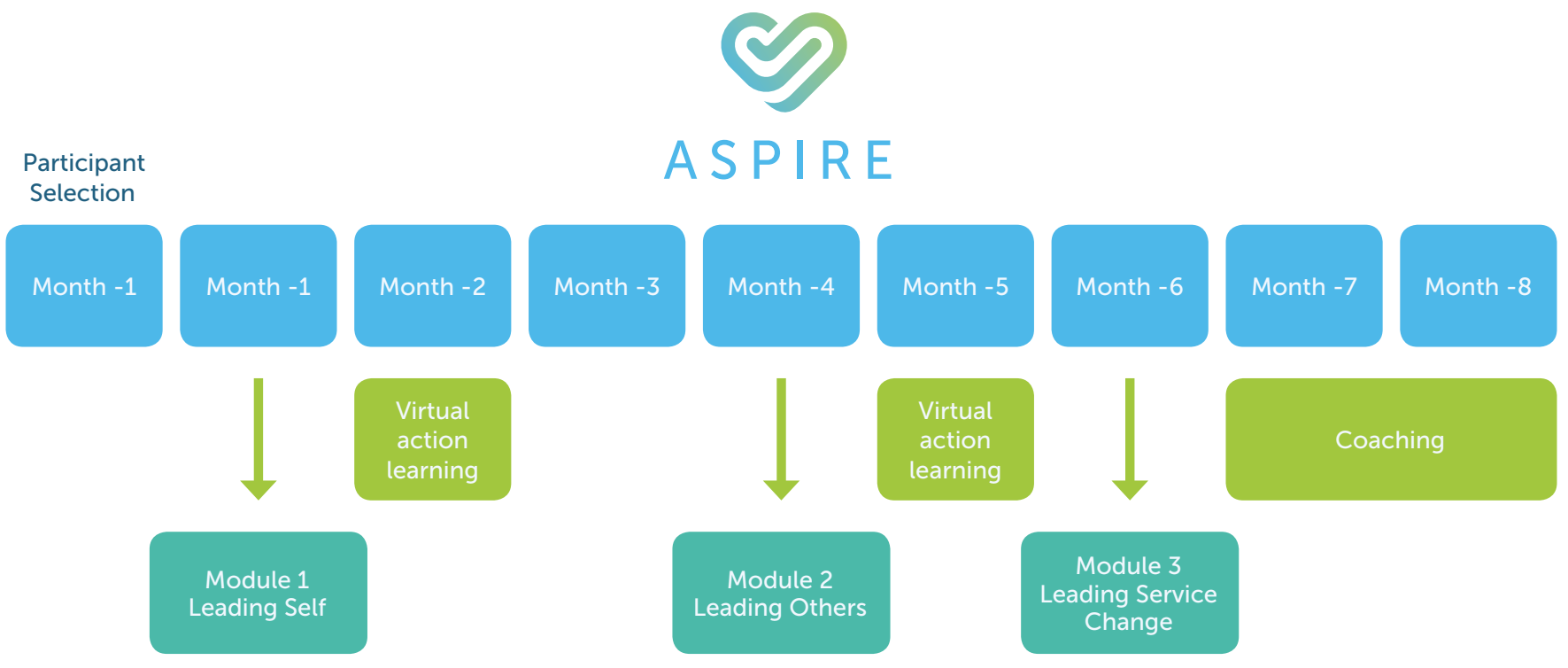

Figure 1. The ASPIRE programme runs over 9 months

generation of haemophilia leaders who are committed to improving haemophilia care across the UK, and beyond. It is aimed at those who wish to lead and influence change in haemophilia care, who wish to influence the people they work with, and who are not afraid to rethink the way that care is delivered. It is for people who see themselves as future clinical and/or service leaders, and who are committed to their own development and the improvement of clinical services.

ASPIRE is open to healthcare professionals from multiple disciplines within the haemophilia care team, including nurses, physiotherapists, social workers, psychosocial therapists and psychologists, and provides the opportunity to be members of an MDT leadership community supporting each other in their leadership roles, and contributing to clinical and educational initiatives in haemophilia. Such initiatives include research, active involvement in the Haemophilia Nurse Association (HNA), World Federation of Hemophilia (WFH) and other appropriate congresses, participation on advisory boards, and leading change within haemophilia centres. It has been designed and sponsored by Haemnet to support clinicians to 'lead as clinicians' in contrast to 'leading as managers' (Panel 1).

\section{What is ASPIRE?}

ASPIRE is a 9-month development programme comprising three workshops (each of 1-1.5 days), interspersed with 2-hour facilitated action learning meetings (held face-to-face or by telephone/Skype/ Facetime), culminating in a coaching session. The modules - 'Leading Self', 'Leading Others' and 'Leading
Service Change' - engage participants in theoretical and practical aspects of leadership, with a focus on applying learnings to the 'real world' of leading haemophilia care.

The modules consider old and new leadership thinking, and the challenges of leading in a complex world, with theoretical perspectives including 'Engaging Leadership' [1], 'Being Yourself with more Skill' [2], and 'Power and Influence, Dynamic Patterning ${ }^{[3]}$, Embodied Leadership' ${ }^{[4]}$ and 'Collaborative Leadership' ${ }^{[5]}$.Alongside these, the Myers-Briggs Type Indicator (www.myersbriggs. org) was used as a tool to support understanding and appreciation of the differences between people and to explore how this influences us as leaders.

During action learning sessions, groups of participants support each other to resolve challenging situations they are experiencing, and review progress in improving haemophilia care services ${ }^{[6]}$. At the end of the course, one-to-one coaching sessions provide an opportunity for participants to identify and focus on their continuing professional development in more detail, with time to reflect on their learning and achievements from the programme.

ASPIRE has been developed by Dr Sharon Varney, a specialist in developing people and organisations and a member of faculty at Henley Business School, University of Reading, and Sandra Dodgson, an experienced collaborative leader currently supporting strategic development at Haemnet.

Selection for ASPIRE is by application, including a 100-word summary on why prospective participants wish to take part in the programme and what they want to achieve in leading haemophilia care. The programme 


\section{Panel 1: The haemophilia nurse's viewpoint: Cathy Harrison}

The ASPIRE programme showed me that you don't need to be a manager to be a leader, and that leaders have many different personalities and skills. It not only gave me new insights into leadership, it also made me a better team player. I gained a greater understanding of when to bring my natural energy to the table and to recognise when to back off! So, although ASPIRE is a leadership course, it's enhanced my clinical practice and my relationships with others in the team where I work.

I am now leading a haemophilia service improvement initiative at my Trust, together with one of the consultants, and what I learned in ASPIRE has helped me to get everyone on board and move things forward. At the start, we looked at what is good and bad about the service and patient feedback, and at specific issues such as whether efficiencies could be made by improving patient pathways. We looked at whether we can make better use of our skills, through more nurse prescribing and nurse-led clinics, and how that can raise the profile of the unit and increase income for the Trust. We've had to work out our priorities, and success will be measured in a number of ways, including reduced waiting times for new patients, better pathways, and improved patient and staff feedback. We're already seeing improvement in some scores.

A big advantage of ASPIRE for nurses who may be thinking of participating is that it's specifically for people working with patients who have bleeding disorders. We can go on NHS courses, but they include nurses from all different specialties who don't know about the specific issues and complex relationships that go with caring for patients with haemophilia, many of whom come from families where generations are affected by the disease and cared for in the same centre.

ASPIRE also enabled us to focus on what we want as a group, and how we can lead and help the younger generation of haemophilia specialists. We often get weighed down by what we do, day-to-day, so it's very useful to see the bigger picture. Following ASPIRE, I feel very much part of a multidisciplinary group, all of us involved in haemophilia and supporting each other as we move forward locally and on the national and international haemophilia stage.

is run annually with small groups of 6-8 people, with the content tailored to the needs and expectations of each cohort of participants.

\section{Evidence-based principles}

Underpinning ASPIRE are core principles of emotional intelligence ${ }^{[7]}$, positive psychology ${ }^{[8]}$ and complexity science ${ }^{[9]}$, which are increasingly used in leadership and organisation development. Emotional intelligence is an individual's capacity to recognise their own and other people's emotions and feelings, to use emotional information to guide thinking and behaviour, and to adapt and adjust to achieve their goals. At an early stage in the ASPIRE programme, participants are encouraged to explore and understand themselves as leaders and how they engage with others; their personal leadership style and leadership vision (Panel 2).

Positive psychology helps individuals to recognise and build on their strengths so that they can work collectively in an effective way. In ASPIRE, positive psychology is an important element in encouraging participants to consider how they might contribute their skills in a leadership role, for example, in facilitating the spread of best practice in haemophilia care across the UK.

Collaborative leadership focuses on achieving results across boundaries, be they within or between organisations ${ }^{[5]}$. During ASPIRE, participants explore how to secure value from difference, share control, and trust a partner to deliver, even though that partner may operate very differently from themselves - something which is at the heart of MDT working.

Complexity science focuses on the dynamics of complex organisations and systems, and how interactions between individual components can impact on collective activities and behaviours. In ASPIRE, complexity science is used, for example, to demonstrate that improvements in haemophilia care are often not as difficult or impossible to achieve as we sometimes believe. Instead, making what may seem like a very small intervention at the right time and place can have a significant impact and make fundamental changes much more achievable, as much of the service improvement work across the NHS has demonstrated. 
Panel 2: The psychologist's viewpoint: Gráinne O'Brien

I was quite new to haemophilia and found the shared learning about leadership opportunities within the MDT very enlightening in helping me build my own haemophilia leadership path. We learned from the facilitators and from each other, and the collaboration and support during face-to-face and telephone and Skype calls through the whole ASPIRE programme was incredibly useful. It was so different from other, shorter courses where you get really enthusiastic for a few hours but then go back to work and don't get around to putting anything into practice. The ongoing contact and support definitely helped me to apply all the new ideas to my daily work.

I am working on a two-year pilot for introducing psychological care into haemophilia services in Scotland, and ASPIRE enabled me to reflect on the strengths I could bring to the project - on my own and by communicating with and leading others. Despite years of training, I had never reflected about what it truly means to be a leader or how to lead effectively and bring people along with you. I discovered that some of the things I had thought were weaknesses are actually strengths, and that it isn't always essential to lead from the front. Communicating effectively, working collaboratively and being authentic are just as important for being a good leader

Psychological services for patients with haemophilia are very varied across the UK and, as a result of ASPIRE, I have set up an email group for psychological therapists to discuss the development of psychological support within haemophilia services. We will meet for the first time in July, which is incredibly exciting. Attending ASPIRE allowed me time to reflect on what is important to me professionally and what type of leader I want to be. Increasing access to emotional support for those with haemophilia is a key aim for me. Organising a meeting for psychological therapists is an important step in moving this forward.

Psychologists spend a lot of time reflecting on and honing our therapeutic skills, but rarely have the opportunity to reflect on ourselves as leaders. ASPIRE is a unique training opportunity that enables psychologists to be embedded in the haemophilia world and helps us to understand what roles we could lead on within that world. The programme brings together a lot of complex ideas in an accessible form. It also supports our development within the psychology community - enabling us to recognise and build our leadership skills, to push forward with and grow psychological services.

Having the confidence to 'think small but effectively' can be the route to success.

\section{What has happened?}

On a personal level, some participants in ASPIRE 2016 found that the programme gave them more confidence in expressing their views and opinions in MDT and other meetings - in 'finding their voice'. They became aware that leadership can be quiet and reflective, and that small, focused contributions to discussions are as valuable as louder, more frequent interventions (Panel 3).

For others, ASPIRE facilitated a shift from thinking that they might have leadership potential to knowing that they were leading and had the skills, knowledge and resilience to be leaders; gaining the confidence to take on leadership roles.

Taking part in ASPIRE 2016 also gave participants space to consider what improvements they could make to haemophilia services in their own centres, and how these might impact on efficiency and budgetary considerations within their Trusts. These included opportunities for better communication with colleagues to improve service delivery, and development of an initiative to improve communication with male patients about safe sexual practices for reducing the risk of bleeds (and potentially treatment costs) embedded in development of their transition services.

During module 3, 'Leading Service Change', participants in ASPIRE 2016 worked together to develop their shared vision for the future of haemophilia services in the UK (Figure 1). They envisaged leading a continued shift from a medical model of care to the comprehensive care model, with the voices of MDT members and people with haemophilia at its heart. To achieve this, they aim to support stronger collaboration between MDT members, and enhance input into research and education. They believe that access to a broader skill mix and knowledge base will result in 
Panel 3: The physiotherapist's viewpoint: Paul McLaughlin

I've tended to steer clear of leadership courses because I have a horror of having to role-play being a bad manager or a disgruntled patient. But ASPIRE was totally different, and it was fun! Working as a multidisciplinary group was very productive because I gained different perspectives on working with patients with haemophilia. If it had been a leadership course just for physiotherapists, we could have had patients with a range of different diseases and that would have been less useful for me as someone working in haemophilia.

The course was also different because we weren't just given books and slides; it wasn't didactic, it was applied. There was a lot of problem sharing and we used active listening and learning to help each other come up with solutions, which I hadn't experienced before and found very helpful. I was glad that ASPIRE happened over several months because we had time to develop ideas for dealing with problems, try them out and then discuss why they had or hadn't worked. As we'd made a positive commitment for almost a year, I found myself regularly thinking about what l'd learned and putting it into practice, instead of feeling guilty because there wasn't time to take action. The one-to-one coaching at the end of the course was also useful, as it gave me an opportunity to talk about medium-term issues with someone who was unbiased and could help me consider possible solutions.

I act differently now in meetings and am more careful to ensure that my contributions are useful and appropriate, so that people are more likely to listen to them. I pay more attention to the quieter people in the room and encourage them to give their opinions. As clinicians, I think we're all eager to give advice based on our knowledge but, through ASPIRE, I realised that you also need to listen and encourage people to find their own solutions.

Physiotherapists are an integral part of the MDT and, going forward, leadership in haemophilia will need to encompass all the specialties that are involved in patient care, including musculoskeletal. It's not about what grade you are or where you are on the pay scale; it's more about who is best placed to lead on development of musculoskeletal services for patients with haemophilia - and that may often be the physiotherapist.

the best possible patient-centred care. This is a vision that will evolve and be taken forward by the growing leadership community participating in ASPIRE (Panel 4).

\section{Conclusions}

The ASPIRE programme has been established to encourage and support a new generation of haemophilia leaders who are committed to improving haemophilia care across the UK, and beyond. It is open to healthcare professionals from multiple disciplines and is designed to support the development of leaders amongst members of the haemophilia care team in a way that contrasts with hierarchical leadership and management courses more typically found in the NHS.

As a result of ASPIRE 2016, participants are now playing an active role in leading change within their own services, as well as leading Haemnet and other professional initiatives, including the 2017 annual HNA meeting and the WFH congress 2018.

ASPIRE is an annual opportunity to engage with colleagues from across the UK and lead changes in practice, and applications are currently being considered for the 2017 programme. It is envisaged that, together with Haemnet, participants will build on the foundations created in 2016 for a vibrant, cross-disciplinary, multinational clinical leadership community that benefits people with bleeding disorders and ensures that 'excellent haemophilia care is an everyday experience'.

\section{Acknowledgments}

The ASPIRE programme was developed by Haemnet with funding from the Burdett Trust for Nursing.

The authors have advised no interests that might be perceived as posing a conflict or bias. This is an Open Access article distributed under the terms of the Creative Commons Attribution License (http:// creativecommons.org/licenses/by/2.0), which permits unrestricted use, distribution, and reproduction in any medium, provided the original work is properly cited.

\section{About Dr Sharon Varney}

Sharon is a practising organisation development consultant and is Director of the Henley Forum at Henley Business School, University of Reading. Sharon 


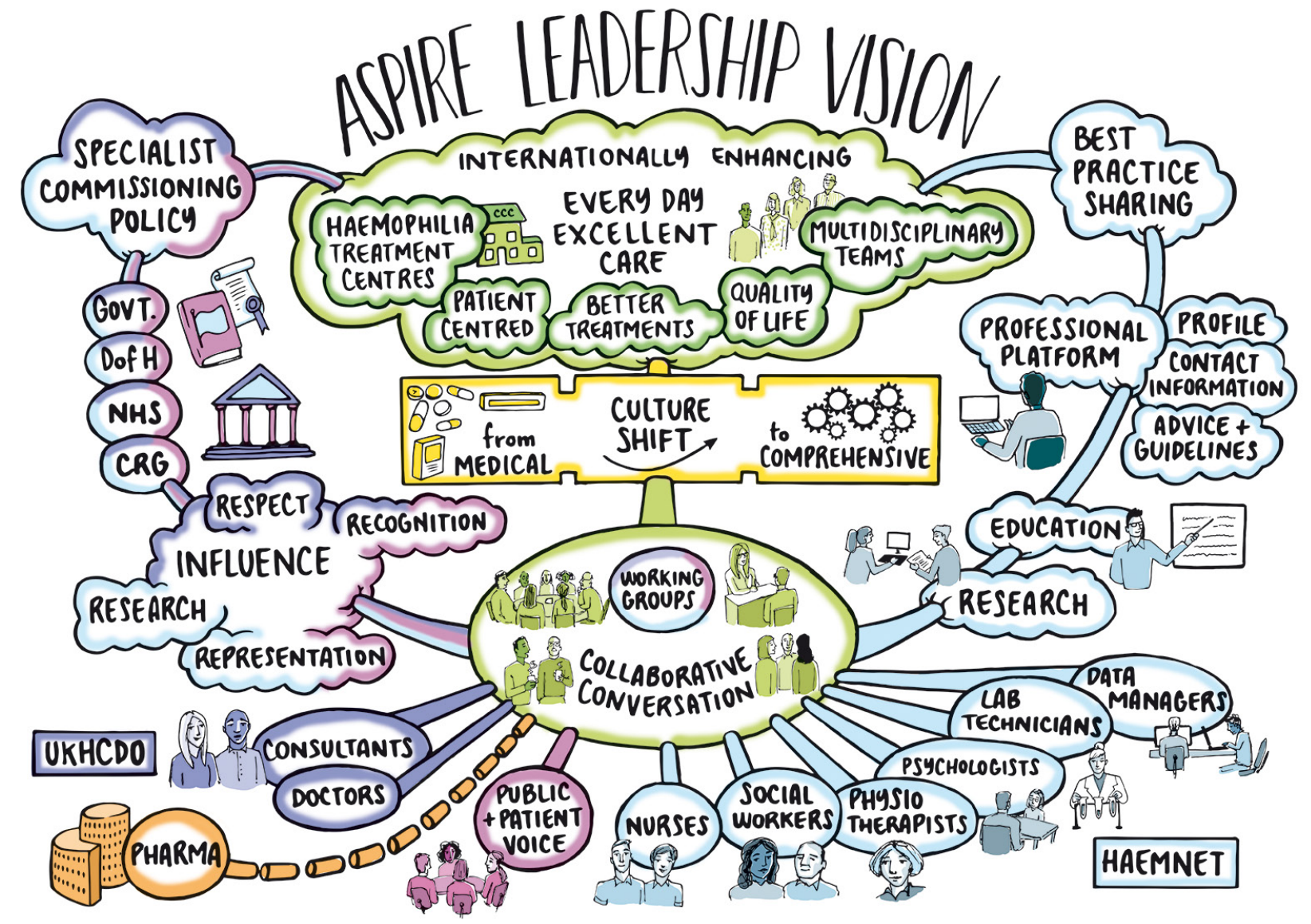

developed her leadership and change expertise working internationally as a senior manager in large, complex organisations, including the global oil and gas business and banking. Her consulting work focuses on leadership and organisational development, and spans across the private, public and not-for-profit sectors. Sharon's research takes a complexity science perspective on organisational change and its leadership. Her awardwinning doctoral research at the University of Reading explored the complex dynamics of organisational change and the role of change leaders within it.

\section{About Sandra Dodgson}

Sandra is a strategic development specialist with a track record of working with groups to achieve shared purposes that make a real difference for the people who use and deliver services. Most recently, she was strategic development director at Bridge Mental Health, a charity that enables people to achieve greater independence and wellbeing across the mental health pathway. She has also worked in the Department of Health, supporting 'policy into practice', the third sector in drug and alcohol services, and advises charities, central government departments, local councils and national professional bodies.

\section{References}

1. Henley Business School, University of Reading. Henley Centre for Leadership. Available from: http://www.henley.ac.uk/ research/research-centres/henley-centre-for-engagingleadership/ (accessed 2 May 2017).

2. Goffee R, Jones G. Why Should Anyone be Led by You? What it Takes to be an Authentic Leader. Boston, MA: Harvard Business School Press, 2006.

3. Varney S. Organisational change: finding your way as you journey into the unknown. HR Network Paper 104, Institute for Employment Studies (2015. Available from: http://www.employment-studies.co.uk/resource/ organisational-change-finding-your-way-you-journeyunknown (accessed 2 May 2017).

4. Hamill P. Embodied Leadership: The Somatic Approach to Developing your Leadership. London: Kogan Page, 2013.

5. Archer D, Cameron A. Collaborative Leadership: How to Succeed in an Interconnected World. Oxford: Butterworth Heinemann, 2008.

6. Revans RW. The ABC of Action Learning: Empowering Managers to Act and to Learn from Action. London: Lemos and Crane, 1998

7. Goleman D. Working with Emotional Intelligence. London: Bloomsbury Publishing, 2009

8. Seligman ME, Csikszentmihalyi M. Positive Psychology: An Ontroduction. New York: Springer, 2014.

9. Allen PM, Maguire S, McKelvey B (ed.). The SAGE Handbook of Complexity and Management. London: Sage Publications, 2011. 
Panel 4: The research nurse's viewpoint: Simon Fletcher

ASPIRE gave me valuable insights into who I am and how I work. I didn't come away with fixed rules for leadership, but I have started to think differently about working within a team and moving things on, instead of just doing my day job. I'm someone who likes to go away and think about a question before I answer, and it was enlightening to discover that's not a weakness, it's just who I am.

NHS leadership and management tend to be from the front, and I used to question how I could lead from a position that wasn't at the top of the hierarchy. However, I've learned that it's possible to lead from behind and that can be just as effective.

As a research nurse, I sometimes feel there's a gap between me and other haemophilia nurses. But, by working with nurses and other members of the haemophilia care team on the ASPIRE course, I feel I'm better able to bridge that gap. As we met over a period of several months, we got to know each other well and we plan to meet up and discuss what progress we're all making.

Since ASPIRE, I've taken more of a lead role within haemophilia research at the centre where I work, and am currently trying to get a shared view of what we do and where we want to go with our research. I'm organising a meeting for all the stakeholders in haemophilia research to review our progress in terms of our achievements, pressures and targets. I'm not trying to dictate what we do, but to facilitate so that we get consensus on how we should move forward. We started the process before ASPIRE, but going on the course has given me more confidence and I now realise that, if you're going to lead on something, you need to own it. I feel more secure about who I am and what I know, and giving my opinion in meetings.

Following the ASPIRE course, I co-led a workshop at the recent HNA conference - as did other participants on the programme. It's daunting to stand up in front of your peers, who you know are very knowledgeable - but ASPIRE made me realise that we all have different expertise and that I may know more about some things than other people, and vice versa. It was still daunting, but it went better than I expected and the feedback suggested that I appeared confident and knew what I was talking about. I would certainly do it again, without hesitation!

\section{The Journal of Haemophilia Practice}

\section{An open-access journal for sharing experience in the care of people with bleeding disorders}

www.haemjournal.com

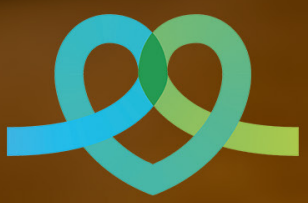

